\title{
Zur Kenntniss der Constitution der Cholsäure von
}

\author{
Dr. med. et phil. Michael Seńkowski,
}

Assistent.

Aus dem Laboratorium für medicinische Chemie in Krakau.

(Vorgelegt in der Sitzung am 5. December 1895.)

Die jetzt angenommene Formel der Cholsäure $\mathrm{C}_{24} \mathrm{H}_{40} \mathrm{O}_{5}$ enthält acht Wasserstoffatome weniger, als wenn sie einer gesättigten Verbindung entspräche. Man muss daher zugeben, dass die Cholsäure eine ungesättigte Verbindung mit doppelten oder dreifachen Bindungen ist oder, dass sie in ihrem Moleküil einen aromatischen Ringcomplex enthalte. Die Entscheidung dieser Frage begegnete ernsten Schwierigkeiten, da das einzige sichere Beweismittel der aromatischen Gruppe, die Erhaltung der Benzolcarbonsäuren durch Oxydation, sich in diesem Falle unzulänglich erwies. Durch schwächere Oxydation wurden die Dehydrochol- und Biliansäure erhalten, die dieselbe Anzahl der Kohlenatome im Molekül besassen, durch stärkere eine Reihe von Verbindungen, wie die Choloidinsäure Redtenbacher's, respective Cholecamphersäure Latschinoff's, Cholansäure Tappeiner's u. A., die aber ebensowenig bekannt sind als die Cholsäure selbst. Auch andere Mittel, wie das von Gorup Berauer angewendete Schmelzen mit Ätzkali führten zu keinem erwünschten Resultate. Derselbe erhielt ausser Essig und Propionsäure eine Verbindung $\mathrm{C}_{19} \mathrm{H}_{30} \mathrm{O}_{3}$, die nicht krystallinisch war und nicht weiter untersucht wurde. ${ }^{1}$ Neuerdings wurde dieselbe Reaction von Lassar Kohn mit ähnlichem Resultate wiederholt. ${ }^{2}$

1 Ann. der Chemie, 157, S. 285.

2 Zeitschr. für physiol. Chemie, 16, S. 490. 
Von Wichtigkeit für diese Frage ist die Einwirkung der Halogene auf Cholsäure. Die Cholsäure selbst kann natürlich nicht derselben unterworfen werden, ohne dass die Halogene auf die drei im Cholsäuremolekül enthaltenen Hydroxyle einwirken. Wenn man aber Cholsäure mit Essigsäureanhydrid kurze Zeit kocht und die resultirende harzige Masse in Chloroformlösung mit Brom versetzt, so wird die Lösung erst nach längerer Zeit entfärbt unter gleichzeitiger Entwicklung des Bromwasserstoffes. Nichts erinnert an die heftige Einwirkung von Brom auf ungesättigte Verbindungen, es bildet sich wahrscheinlich nur ein Substitutionsproduct. Bei der Einwirkung von Brom auf Dehydrochol und Biliansäure, die dieselben doppelten, respective dreifachen Bindungen enthalten müssten, bilden sich nach Landsteiner nur Substitutionsproducte. ${ }^{1}$ Es ist also kaum anzunehmen, dass die Cholsäure eine ungesättigte offene Kette besitze; es bleibt daher nichts übrig, als den Benzolkern zu suchen. Angesichts dessen wurde noch einmal ein Oxydationsversuch, und zwar mit Kaliumpermanganat in alkalischer Lösung vorgenommen.

$25 \mathrm{~g}$ krystallinische, ganz reine, nach Mylius erhaltene Cholsäure wurde in genügender Menge Kalilauge gelöst, die Lösung durch Erwärmen von Alkohol befreit und ihr eine concentrirte Permanganatlösung unter gleichzeitigem Erwärmen im Wasserbade nach und nach zugegossen, bis eine Probe der vom Mangandioxyd abfiltrirten Flüssigkeit nach dem Ansäuern mit Salzsäure keine im Wasser unlöslichen Säuren mehr ausschied. Die verbrauchte Menge des Permanganats betrug circa $180 \mathrm{~g}$. Das Oxydationsproduct wurde von dem ausgeschiedenen Mangandioxyd abfiltrirt, durch Abdampfen concentrirt, mit Salzsäure im Überschusse versetzt und mit Wasserdampf destillirt. Das Destillat reagirte sauer und in demselben wurden kleine Mengen von Essig und wahrscheinlich Propionsäure gefunden, von Benzoesäure aber war keine Spur vorhanden. Der Destillationsrückstand wurde mehrmals mit Äther ausgeschüttelt und der Äther abdestillirt. Es blieb eine syrupartige, saure, im Wasser leicht lösliche Masse, aus der sich nach einigen

1 Zeitschr. für physiol. Chemie, 19, S. 285. 
Stunden lange Krystallnädelchen ausschlossen. Die Krystalle wurden abgesaugt, mit kleinen Mengen von Äther, worin sie ziemlich schwer löslich waren, gewaschen und aus heissem Wasser umkrystallisirt. Sie schmolzen bei $105^{\circ}$. In der Voraussetzung, dass es sich doch um die Benzoesäure handelt, wurden dieselben der Sublimation unterworfen. Die Substanz sublimirte unter Wasserausscheidung, und der Schmelzpunkt erhob sich auf $180^{\circ}$, war aber nicht constant. Nach mehrmaligem Sublimiren, wobei sich immer Wassertröpfchen zeigten, wurden lange Krystallnadeln erhalten, die constant bei $128^{\circ}$ schmolzen. Der Schmelzpunkt zeigte, dass es sich um Phtalsäureanhydrid handelt, was die ausgeführte Fluoresceinreaction bestätigt hat, die nach dem Schmelzen der Krystalle mit Resorcin und nachherigem Lösen in verdünntem Ammoniak hervortrat.

Die Elementarenalyse der Krystalle ergab:

$$
\begin{aligned}
& \mathrm{C} \ldots \ldots 64 \cdot 42 \% \\
& \mathrm{H} \ldots \ldots 3 \cdot 05
\end{aligned} \quad \begin{gathered}
\begin{array}{c}
\text { Berechnet } \\
\text { für } \mathrm{C}_{8} \mathrm{H}_{4} \mathrm{O}_{3}
\end{array} \\
\begin{array}{c}
64 \cdot 86 \% \\
2 \cdot 74
\end{array}
\end{gathered}
$$

Aus dem Vorgeführten scheint es mir unzweifelhaft $z u$ sein, dass die Cholsäure in ihrem Molekül eine Orthophenylengruppe enthalte. Man könnte zwar einwenden, dass die Phtalsäure durch Oxydation der zuerst gebildeten Benzoesäure entstehen kann; indessen scheint es mir kaum möglich, ohne dass unter den beschriebenen Verhältnissen nicht wenigstens eine Spur von Benzoesäure zurückgeblieben wäre, welche jedoch durch den Destillationsversuch mit Wasserdämpfen vollständig ausgeschlossen wurde. Es wäre nun zu bestimmen die Structur der beiden Seitenketten der Cholsäure, mit welcher Arbeit ich eben beschäftigt bin.

Schliesslich erlaube ich mir dem Herrn Prof. Dr. Stopczański für seinen mir im Laufe dieser Arbeit gütigst ertheilten Rath meinen innigsten Dank auszusprechen. 